\title{
CONSELHOS DE ADMINISTRAÇÃO E BOARD INTERLOCKING ENTRE AS EMPRESAS LISTADAS NO NÍVEL 1 DE GOVERNANÇA CORPORATIVA DA B3
}

\author{
BOARD OF DIRECTORS AND BOARD INTERLOCKING BETWEEN COMPANIES LISTED ON \\ CORPORATE GOVERNANCE LEVEL 1 OF B3
}

Recebido em 12.11.2019 Aprovado em 23.06.2020 Avaliado pelo sistema double blind review DOI: https://doi.org/10.12712/rpca.v14i2.38627

\section{Fábio Pagliarini do Nascimento}

fabiopgn1@hotmail.com

Programa de Pós-Graduação em Engenharia de Produção/Universidade Federal de São Carlos -Sorocaba/SP,Brasil https://orcid.org/0000-0002-1602-5881

\section{Patrícia Saltorato}

patriciasaltorato@gmail.com

Programa de Pós-Graduação em Engenharia de Produção/Universidade Federal de São Carlos -Sorocaba/SP,Brasil https://orcid.org/0000-0002-4089-2547

\section{Tiago Fonseca Albuquerque Cavalcanti Sigahi}

tiagosigahi@usp.br

Programa de Pós-Graduação em Engenharia de Produção/Universidade de São Paulo - São Paulo/SP, Brasil

https://orcid.org/0000-0002-2595-5220

\section{Geraldo Tessarini Junior}

geraldo.tessarini@gmail.com

Programa de Pós-Graduação em Engenharia de Produção/Universidade Federal de São Carlos -Sorocaba/SP,Brasil https://orcid.org/0000-0002-4376-4487

\section{Resumo}

Este trabalho explora o board interlocking (BI) a partir da análise das redes sociais formadas pelos conselhos de administração (CA) das empresas do Nível 1 de Governança Corporativa da B3. Os dados foram coletados por meio de pesquisa documental junto à imprensa de negócios e órgãos especializados, e analisados considerando medidas de centralidade de grau, intermediação e proximidade. Constatou-se que $42 \%$ dos conselheiros atuam simultaneamente em mais de um CA e que $92 \%$ das empresas possuem interlocking (pelo menos um executivo). Compreender o BI permite que pesquisadores, gestores e acionistas tomem decisões mais assertivas, respeitando os limites legais e éticos.

Palavras-chave: Governança corporativa. Conselho de administração. Board interlocking. Bolsa de valores.

\begin{abstract}
This paper explores board interlocking (BI) through social networks analysis of the boards of directors of companies listed in Level 1 of Corporate Governance in B3. Data were collected through documentary research in business press and specialized agencies, and analyzed considering measures of centrality (degree, closeness, betweenness). It was found that $42 \%$ of the directors work simultaneously in more than one board of directors and that $92 \%$ of the companies have interlocking (at least one executive). Understanding BI allows researchers, managers and shareholders to make more assertive decisions, respecting legal and ethical limits.
\end{abstract}

Keywords: Corporate Governance. Board of Directors. Board interlocking. Stock exchange. 


\section{Introdução}

O conflito de interesses e a consequente necessidade de diminuir a falta de alinhamento formada por um ambiente de separação entre os acionistas (principal) e a gerência (agente) das empresas é um tema já amplamente difundido na literatura nacional e internacional, sobretudo sob os preceitos da Teoria da Agência (SONZA; KLOECKNER, 2014). Nesse cenário, nasce a Governança Corporativa (GC) com o objetivo de proporcionar mecanismos de controle, proteção e transparência nas relações entre o principal e o agente, buscando eliminar ou reduzir o conflito de agência (ASSUNÇÃO; MENDES DE LUCA; VASCONCELOS, 2017).

Nesse complexo ambiente de separação, o Conselho de Administração (CA) funciona como um dos principais métodos internos de governança na busca por harmonização entre os interesses dos administradores e dos proprietários (NISIYAMA; NAKAMURA, 2018). Algumas de suas atribuições mais relevantes se referem ao monitoramento dos gestores das empresas, à validação das principais decisões e ao estabelecimento de diretrizes estratégicas que concernem à companhia (SANTOS; SILVEIRA, 2007). Para garantir a integridade e imparcialidade dessas decisões, os códigos mais relevantes de boas práticas de governança, destacam a importância da independência dos conselhos administrativos, assim como da fragmentação dos cargos de diretoria executiva e presidência do CA por diferentes gestores (IBGC, 2015; CVM, 2002; OECD, 2017).

Entretanto, a presença de conselheiros externos à empresa (independentes) aumenta a possibilidade de esses membros atuarem em mais de um conselho administrativo, configurando, assim, o fenômeno do board interlocking (BI): uma rede de empresas que se conectam através da participação dos executivos em múltiplos conselhos (DAL VESCO; BEUREN, 2016; SANTOS; SILVEIRA, 2007). Em outras palavras, o BI consiste no fato de um profissional ocupar a posição de conselheiro em, no mínimo, duas empresas, proporcionando a formação de uma ligação (rede) entre elas (CUNHA; PICCOLI, 2017; GOMES; BEUREN; VICENTE, 2019).

Estudos sobre BI têm sido realizados há décadas no âmbito da GC, evidenciando suas contradições, limitações e possibilidades (FICH; WHITE, 2005; CUNHA; PICCOLI, 2017). A literatura mais recente aborda aspectos como a ocorrência do BI em setores específicos da indústria, buscando entender suas especificidades (BUEREN; DANI, BECK, 2014), a relação entre o BI e as práticas de suavização de resultados (RIBEIRO; COLAUTO, 2016), a influência do BI na performance, nos lucros e no gerenciamento de resultados das empresas (DAL VESCO; BEUREN, 2016; CUNHA; PICCOLI, 2017; LUNARDI; BARBOSA; CUNHA, 2019), as características e a diversidade na composição dos conselhos de administração (FRAGA; SILVA, 2012; NISIYAMA; NAKAMURA, 2018; GOMES; BEUREN; VICENTE, 2019; LAZZARETTI; PIEKAS; JULKOVSKI, 2019) e os reflexos de expertises financeira e política dos conselheiros (MAGRO; KLANN, 2020).

Este artigo tem como objetivo explorar a composição dos conselhos de administração das empresas listadas no Nível 1 de Governança Corporativa (N1-GC) da B3 (Bolsa de valores oficial do Brasil), a fim de analisar a formação do fenômeno do board interlocking e das redes sociais dele derivadas. Entende-se que a pesquisa ganha relevância ante as lacunas existentes na literatura nacional na área de gestão, visto que, apesar de recomendações presentes na literatura (SCHMILIVER et al., 2019), na efetivação deste estudo não foi encontrada nenhuma pesquisa semelhante que buscasse, efetivamente, evidenciar o BI no âmbito das empresas listadas no N1-GC, sobretudo por meio da análise de redes sociais. 


\section{Referencial teórico}

\section{Governança Corporativa}

Para o Instituto Brasileiro de Governança Corporativa (IBGC, 2015), em qualquer tipo de empresa há pelo menos dois interesses em jogo que devem ser considerados e alinhados para evitar a incidência de conflitos: os dos gestores e os dos proprietários. Esse conflito é documentado desde 1932, por Berle e Means, e posteriormente pela Teoria da Agência, defendida por Jensen e Meckling (SONZA; KLOECKNER, 2014; ASSUNÇÃO; MENDES DE LUCA; VASCONCELOS, 2017).

Já o conceito de Governança Corporativa, derivado do inglês Corporate Governance, surgiu na década de 90, principalmente em decorrência do movimento de acionistas e investidores nos EUA que, com o objetivo de se proteger desses conflitos, buscaram o estabelecimento de regras e de um sistema de monitoramento que impedissem tais transtornos e garantissem a transparência e a longevidade do negócio, além de considerar os interesses de todas as partes que estão envolvidas na empresa (SANTOS, 2015).

A premissa, portanto, que orienta a adoção de práticas de GC é a de que as pessoas que estão dentro das empresas podem não agir necessariamente visando os melhores interesses dos proprietários (SONZA; KLOECKNER, 2014). Assim, ela se compõe de um "conjunto de práticas que tem por finalidade otimizar o desempenho de uma companhia ao proteger todas as partes interessadas, tais como investidores, empregados e credores, facilitando o acesso ao capital" (CMV, 2002, p.1).

Nessa mesma linha, o IBGC (2009) aponta que pelas boas práticas de GC os princípios básicos são convertidos em recomendações objetivas, alinhando interesses com objetivos de preservar, em longo prazo, o valor econômico da companhia, facilitar acesso a recursos e contribuir para a qualidade da gestão. Esses princípios estão relacionados à: $\imath$ ) transparência quanto à divulgação de informações entre os interessados de forma clara e legítima; ii) equidade, onde independentemente da posição ocupada pelos membros da companhia, estes devem ser tratados de maneira justa e igualitária; iii) prestação de contas, por meio da qual os agentes devem se responsabilizar por seus atos e apresentar os resultados de sua gestão; e, por fim, $i v$ ) responsabilidade corporativa que, visando a perpetuidade da empresa, descreve a implantação de ações sociais e ambientais na entidade (IBCG, 2015).

\section{Conselho de Administração e board interlocking}

O Conselho de Administração é concebido como um dos principais mecanismos internos das empresas para exercer a GC, sendo responsável pelo monitoramento dos gestores, pela ratificação de decisões e pela fixação de diretrizes estratégica (SANTOS; SILVEIRA, 2007; COSTA; SAMPAIO; FLORES, 2019). Segundo o IBCG (2015, p. 39):

O conselho de administração é o órgão colegiado encarregado do processo de decisão de uma organização em relação ao seu direcionamento estratégico. Ele exerce o papel de guardião dos princípios, valores, objeto social e sistema de governança da organização, sendo seu principal componente. [...] compete ao conselho de administração, conforme o melhor interesse da organização, monitorar a diretoria, atuando como elo entre esta e os sócios.

As características dos CA, tais como o seu tamanho e nível de independência, bem como sua diversidade de gênero, de idade, de escolaridade e de experiências têm sido objeto de variadas pesquisas que, a depender das circunstâncias e o do modelo de negócios, apontam tanto influencias positivas quanto negativas sobre os resultados e o desempenho da firma (DAL VESCO; BEUREN, 2016; NISIYAMA; NAKAMURA, 2018). Analisando algumas dessas variáveis Lazzaretti, Piekas e Julkovski (2019) 
identificam que a diversidade de gênero e o tamanho do CA são as únicas que exercem influência positiva sobre o desempenho organizacional, o mesmo não ocorrendo com outras características, como formação acadêmica e até mesmo a proporção de conselheiros independentes. Em contraste, os autores também constatam que tal aspecto não exclui a ocorrência de dominação e hegemonia masculina na composição dos CA, especialmente nos cargos de presidência e vice-presidência. Dessa forma, como ressaltam Costa, Sampaio e Flores (2019) quanto à participação feminina nos CA, é necessário que o tema seja visto sob uma lógica de senso de justiça e não puramente econômica.

As atividades exercidas pelos conselheiros compreendem não somente o cuidado com os interesses dos investidores, mas também o direcionamento das estratégias dos negócios, de modo que tais interesses sejam garantidos e os objetivos alcançados (SANTOS; SILVEIRA, 2007; GOMES; BEUREN; VICENTE, 2019). Para tanto, a imparcialidade e independência dos CA é uma das práticas mais relevantes de governança (IBGC, 2015). Entretanto, essa busca por independência pode desencadear o fenômeno do BI, com a participação de executivos em múltiplos conselhos (LUNARDI; BARBOSA; CUNHA, 2019). Tanto na literatura nacional quanto internacional, os estudos sobre BI têm sido efetivados há décadas, evidenciando suas contradições, limitações e possibilidades (FICH; WHITE, 2005; CUNHA; PICCOLI, 2017).

Em uma perspectiva positiva, Fich e White (2005) descrevem o BI como um resultado das leis do mercado, em que os conselheiros mais competentes são visto como recursos escassos e, portanto, existiria uma disputa natural entre as firmas por eles. Para Schoorman, Bazerman e Atkin (1981) uma das justificativas para a ocorrência desse fenômeno é a sua utilização como meio de aperfeiçoamento das relações contratuais entre as firmas, o que contribui para a redução das incertezas implícitas aos negócios. Nesse mesmo sentido, Nicholson, Alexander e Kiel (2004) ressaltam que ele é especialmente vantajoso para companhias que enfrentam cenários de complexidade organizacional, incertezas e interdependência, pois seria um mecanismo que combateria eventuais desvantagens provenientes destes fatores por meio da coesão social dos conselheiros e de sua influência no ambiente de mercado.

Além disso, o interlocking pode contribuir para a dispersão de práticas de governança, por meio do compartilhamento de informações e experiências entre conselhos, de forma que um conselheiro pode levar práticas presentes em uma empresa para a outra e, quanto maior a sua conexão, maior poderá ser esse compartilhamento, exercendo papel decisivo na determinação de estratégias e na superação das incertezas dos investidores (CONNELY et al, 2011; RIEIRO; COLAUTO, 2016; CUNHA; PICCOLI, 2017;). Algumas práticas decorrentes são o aumento de contatos clientes, fornecedores e credores, expandindo a rede de interação social da empresa (SANTOS; SILVEIRA, 2007). Isso pode conduzir a um importante processo de aprendizagem organizacional, a partir de conhecimento e aplicação das melhores práticas compartilhadas nas redes (RIBEIRO; COLAUTO, 2016), possibilitando não somente a redução das incertezas, mas também a garantia de recursos, o acesso a novas oportunidades e a própria legitimidade das práticas e decisões (MAGRO; KLANN, 2020).

Por outro lado, o maior compartilhamento de informações entre os conselheiros pode incorrer no risco de mimetismo na adoção de práticas discricionárias ou à adoção de comportamentos éticos duvidosos (RIBEIRO; COLAUTO, 2016). Outra grande crítica apontada ao BI é a evidente escassez de tempo que os conselheiros dedicam às companhias (visto que precisam atuar em múltiplos conselhos), o que também pode representar, de alguma maneira, fragilidades na defesa dos interesses dos acionistas dessas companhias (SANTOS; SILVEIRA, 2007; CUNHA; PICCOLI, 2017). Fich (2005) relata em seu estudo que após o anúncio participação de conselheiros em outros conselhos as ações das empresas passam a apresentar retornos negativos, o que pode indicar o temor dos investidores em relação à proteção de seus interesses. Loderer e Peyer (2002) documentam em seu estudo que o acúmulo de assentos, isto é, de cargos em outros conselhos de administração, se relaciona de forma negativa ao valor da firma. Os autores justificam que o possível motivo deste resultado é devido aos conflitos de interesses induzido pela variedade de diretorias, além das limitações de tempo que os diretores enfrentam. 


\section{Redes sociais}

De acordo com Freitas (2010), o estudo de redes é de grande interesse científico, tendo em vista a capacidade de uma rede representar problemas reais por meio de modelagem. Para o autor, diversos são os tipos de redes que podemos estudar, sendo uma delas as redes sociais, que são compostas por indivíduos ligados por uma ou mais características de interdependência, tais como relações afetivas ou de parentesco, comerciais, poder, conhecimento ou prestígio.

A formação de uma rede social se dá por um conjunto de atores, denotados nós da rede, e suas ligações, distinguindo-se redes de um e dois modos. No primeiro caso, o estudo ocorre em um conjunto de atores similares, por exemplo, pessoas, organizações e grupos sociais. Porém, muitas redes sociais têm a características de dois modos, onde os nós são separados em dois conjuntos (TOMAEL; MARTELETO, 2013). Entre essas características, Borgatti (2009) explica que a denotação "modo" se refere à classe de entidades - assim chamadas de atores, nós ou vértices -, em que os membros se conectam com outros membros. Nesse sentido, caso o relacionamento seja com membros da mesma classe, a rede é de "um modo", em contrapartida, ligações com membros de outra classe, caracterizam redes de "dois modos".

Subjacente ao conceito de redes sociais está o entendimento dos processos interativos e um método de análise, sendo o principal a compreensão da estrutura social pelo estudo das interações e dos fenômenos que concernem às redes. Por exemplo, a entrada de um ator na rede e sua posição na estrutura em análise permite estudar as interconexões organizacionais, que por sua vez possibilita a observação de fenômenos complexos, entre elas, as relações de poder, o fluxo de informação e a distribuição de recursos (FONTES; STELZIG, 2004).

Grossetti e Bès (2003) apontam que a Análise de Redes Sociais (ARS) é tipicamente usada no estudo de redes "invisíveis", informais, espontâneas e não intencionais procedentes das inter-relações em sociedade. Para Tomael e Martelet (2013), a ARS é a metodologia que detém recursos analíticos para conhecimento e mapeamento das ligações entre indivíduos e diversas entidades, permitindo estudar a estrutura das conexões que existem nas redes.

Freitas (2010) expõe que uma rede pode ser representada matematicamente por um objeto denotado grafo, que é formado por um conjunto de pontos (nós ou vértices), que se ligam por linhas que expressam as relações entre nós (arestas). No contexto de redes sociais, vértices são atores e as arestas as suas relações. Em um modo geral, os atores mais importantes são aqueles que estão frequentemente envolvidos com outros atores, tornando-se mais visíveis e centrais.

A ARS possui um conjunto de métricas que auxiliam a compreensão das relações entre entidades de uma rede. Ao longo das décadas, com o objetivo de medir a variação da importância dos vértices, pesquisadores de redes introduziram várias medidas de centralidade (FREITAS, 2010). Freeman (1978), ao abordar o conceito de centralidade, revisou um grande número de medidas, sintetizando-as em três definições: centralidade de grau (degree centrality) que mede a influência direta entre vértices; centralidade de proximidade (closeness centrality) que está relacionada ao tempo que uma informação leva para ser distribuída por todos os vértices; e centralidade de intermediação (betweenness centrality) que envolve a capacidade de comunicação e intermediação de um vértice entre pares de vértices da rede.

\section{Procedimentos metodológicos}

Para a consecução dos objetivos deste estudo, realizou-se uma pesquisa de cunho teórico-documental, por meio dos seguintes métodos de coleta de dados:

- Pesquisa bibliográfica: contemplaram-se os conceitos de board interlocking (BI) e Governança Corporativa (GC) através da produção acadêmica nacional e internacional, por meio de artigos 
publicados em periódicos e anais de congressos e outros eventos científicos, além de monografias, dissertações e teses que abordam tais temas;

- Pesquisa documental: contemplaram-se (i) Documentos oficiais da Bolsa de Valores nacional (B3); (ii) Documentos oficiais da Comissão de Valores Mobiliários - CVM (formulários de referência das companhias) para identificação da composição dos conselhos de administração das empresas; (iii) Recomendações de instituições representativas como o Instituto Brasileiro de Governança Corporativa (IBGC); e (iv) Imprensa de negócios internacional, como o sítio Bloomberg, como fonte para o levantamento de informações dos conselheiros, tais como formação acadêmica, experiências atuais e participação em conselhos administrativos.

Os dados foram coletados entre fevereiro e junho de 2018. Na ocasião, foram constatadas 26 empresas listadas no N1-GC da B3. Entretanto, neste estudo são analisadas apenas 25, visto que uma das companhias foi excluída devido a não disponibilidade do formulário de referência no sítio da CVM durante a etapa de levantamento.

Para fins de determinação da participação nos conselhos de administração, adotou-se um padrão durante toda a fase de coleta, de modo a permitir a replicabilidade da pesquisa e aumentar sua validade externa. Foi considerado como conselheiro quando constatado na descrição curricular do executivo em vOz presente, no sítio da Bloomberg, os termos Board of Director, Administrative Council, Executive Board e Management Board. Além disso, foi considerado conselheiro ativo quando constatado a expressão Board Member, e, conjuntamente no formulário de referência da CVM, fosse possível identificar a participação no conselho administrativo na mesma companhia.

Para tratamento dos dados obtidos, foi utilizada a ferramenta de edição de planilhas eletrônicas Excel. Além disso, utilizou-se o Microsoft Power BI para proporcionar maior facilidade na identificação das redes sociais, as quais, por sua vez, foram analisadas e representadas em grafos através do software de análise e visualização de redes Gephi.

\section{Resultados e discussões}

\section{Requisitos Legais do Nível 1 de Governança Corporativa da B3}

De acordo com a B3, as empresas listadas na bolsa de valores e que adotam o Nível 1 de GC devem adotar práticas que favoreçam a transparência e o acesso a informação aos investidores, divulgando informações adicionais às sujeitas em lei, como o calendário anual de eventos corporativos e o comprometimento a manter ao menos $25 \%$ das ações em circulação no mercado. Entre outras obrigações descritas em seu regulamento de listagem referente à composição de seus conselhos de administração, estão:

- Vedação à acumulação de cargos: Os cargos de diretor presidente ou principal executivo da companhia e presidente do conselho de administração (Chairman), não poderão ser acumulados pela mesma pessoa. Excepcionalmente e para fins de transição, o acúmulo desses cargos só poderão ocorrer pelo prazo máximo de três anos a partir início da negociação dos valores mobiliários no N1-GC. Entretanto, mediante solicitação formal da companhia, o Diretor Presidente da BM\&FBOVESPA poderá conceder um período maior para cumprimento desta vedação (BM\&FBOVESPA, 2011).

- Divulgação de cargos: Os conselheiros da companhia deverão divulgar a lista de cargos que ocupem nos conselhos de administração, conselho fiscal, comitês e órgão executivos de demais entidades, em até cinco meses após o fim do exercício social, e quando da realização de ofertas púbicas de valores mobiliários (BM\&FBOVESPA, 2011). 
- Prazo máximo de mandato: Os membros do conselho de administração poderão ter mandato máximo de dois anos, com permissão de reeleição. Excepcionalmente e para fins de transição, este mandato unificado poderá uma única vez corresponder a três anos, quando deixar de existir um acionista controlador titular de mais de 50\% do capital votante da empresa (BM\&FBOVESPA, 2011).

- Composição: Conforme o Art. 140 da Lei das sociedades por ações: “O conselho de administração será composto por, no mínimo, 3 (três) membros, eleitos pela assembleia-geral e por ela destituíveis a qualquer tempo". Já o IBGC (2015) traz como recomendação que haja um número impar de conselheiros, entre 5 e 11 executivos.

Entretanto, diferentemente de outros níveis de listagem, como por exemplo o Nível 2 GC, não há a necessidade de uma fração mínima de conselheiros independentes. Contudo, os principais códigos de GC destacam a importância da formação independente dos conselhos administrativos, para garantir a integridade e imparcialidade nas decisões.

No que diz respeito ao BI, o regulamento de listagem da B3 não possui impedimentos e sanções para tratar o tema. Entretanto, em seu $5^{\circ}$ Código de melhores práticas, o IBGC (2015) fundamenta os conselhos interconectados, orientando que as organizações sejam informadas de qualquer potencial conflito de interesses que possa ser gerado pela atuação dos seus conselheiros ou membros do comitê executivo em outras empresas. Conforme descrito nos códigos do IBGC:

Ao assumir uma cadeira em um Conselho de Administração, o conselheiro deve ter em mente não apenas os deveres fiduciários de diligência, de lealdade e de informar, previstos em lei, mas também a responsabilidade assumida com as partes interessadas, que contam com seu comprometimento e participação atenta para que o valor da organização seja preservado e elevado ao longo do tempo (IBGC, 2009, p. 34).

Deve informar os demais membros do conselho sobre quaisquer outros conselhos (de administração, fiscal e/ou consultivo) dos quais faça parte, bem como eventuais consultorias que realize (IBGC, 2009, p. 40). Caso o conselho identifique conflito de interesses de algum de seus membros, os demais conselheiros devem avaliar a conveniência da continuidade desse membro e submeter o assunto à assembleia geral" (IBGC, 2015, p. 53).

O objetivo, nesse caso, não é apenas verificar a existência de conflito de interesses, mas também se o executivo possui a disponibilidade de tempo necessário às atividades. Por essa razão, apesar da não vedação, é recomendável às firmas o estabelecimento de um quantitativo máximo de ocupação de conselheiros em outros conselhos, comitês e cargos executivos (IBCG, 2015).

\section{Composição dos Conselhos de Administração das Empresas do Nível 1 de GC da B3}

O segmento de atuação, o número de executivos que configuram os respectivos conselhos administrativos e o quantitativo de conselheiros independentes nestes conselhos foram identificados para cada uma das 25 empresas que compõem a amostra deste estudo e são apresentados na Tabela 1. Ressaltase que os resultados representam, tão somente, a realidade encontrada no momento da coleta de dados, uma vez que alterações posteriores não estão descartadas. 
Fábio Pagliarini do Nascimento, Patrícia Saltorato, Tiago Fonseca Albuquerque Cavalcanti Sigahi e Geraldo Tessarini Junior

Tabela 1 - Empresas, composição dos conselhos de administração e conselheiros independentes

\begin{tabular}{|c|c|c|c|c|c|}
\hline \multirow{2}{*}{ Empresa } & \multirow{2}{*}{ Setor } & \multirow{2}{*}{ Nome da empresa } & \multicolumn{3}{|c|}{$\begin{array}{l}\text { Conselheiros } \\
\end{array}$} \\
\hline & & & Total & Independentes & $\%$ Independentes \\
\hline A & Comércio & LOJAS AMERIC & 6 & 0 & $0,0 \%$ \\
\hline $\mathrm{B}$ & Comércio e Distribuição & P.ACUCAR-CBD & 11 & 4 & $36,4 \%$ \\
\hline $\mathrm{C}$ & \multirow{7}{*}{ Energia Elétrica } & CEEE-D & 7 & 0 & $0,0 \%$ \\
\hline $\mathrm{D}$ & & CEEE-GT & 6 & 0 & $0,0 \%$ \\
\hline $\mathrm{E}$ & & CEMIG & 15 & 2 & $13,3 \%$ \\
\hline $\mathrm{F}$ & & CESP & 7 & 0 & $0,0 \%$ \\
\hline G & & COPEL & 9 & 3 & $33,3 \%$ \\
\hline $\mathrm{H}$ & & ELETROBRAS & 9 & 2 & $22,2 \%$ \\
\hline $\mathrm{I}$ & & TRAN PAULIST & 9 & 1 & $11,1 \%$ \\
\hline $\mathrm{J}$ & \multirow{4}{*}{ Intermediários Financeiros } & BANCO PAN & 15 & 5 & $33,3 \%$ \\
\hline $\mathrm{K}$ & & BRADESCO & 9 & 0 & $0,0 \%$ \\
\hline $\mathrm{L}$ & & ITAUSA & 6 & 0 & $0,0 \%$ \\
\hline M & & ITAUUNIBANCO & 13 & 5 & $38,5 \%$ \\
\hline $\mathrm{N}$ & Madeira e Papel & EUCATEX & 7 & 0 & $0,0 \%$ \\
\hline $\mathrm{O}$ & \multirow{2}{*}{ Material de Transporte } & FRAS-LE & 6 & 0 & $0,0 \%$ \\
\hline $\mathrm{P}$ & & RANDON PART & 6 & 0 & $0,0 \%$ \\
\hline$Q$ & Mineração & BRADESPAR & 6 & 1 & $16,7 \%$ \\
\hline $\mathrm{R}$ & Químicos & BRASKEM & 13 & 4 & $30,8 \%$ \\
\hline $\mathrm{S}$ & \multirow{4}{*}{ Siderurgia e Metalurgia } & FERBASA & 9 & 0 & $0,0 \%$ \\
\hline $\mathrm{T}$ & & GERDAU & 7 & 3 & $42,9 \%$ \\
\hline $\mathrm{U}$ & & GERDAU MET & 7 & 3 & $42,9 \%$ \\
\hline $\mathrm{V}$ & & USIMINAS & 12 & 5 & $41,7 \%$ \\
\hline W & Tecidos, Vestuário e & ALPARGATAS & 7 & 0 & $0,0 \%$ \\
\hline $\mathrm{X}$ & Calçados & CEDRO & 12 & 0 & $0,0 \%$ \\
\hline $\mathrm{Y}$ & Telecomunicações & $\mathrm{OI}$ & 7 & 6 & $85,7 \%$ \\
\hline
\end{tabular}

Fonte: Elaborado pelos autores (2019).

As empresas analisadas estão presentes em vários segmentos de atuação. Apesar disso, nota-se a concentração nos setores de energia elétrica, financeiro e siderúrgico, perfezendo cerca de $60 \%$ da amostra. Ao todo foram encontrados 221 conselheiros para as 25 empresas, sendo que 44 são conselheiros independentes. Todavia, considerando o BI (discutido na próxima seção) entre as empresas listadas nesse segmento, há 199 conselheiros distintos, uma vez que alguns deles estão vinculados a mais de um conselho.

Em relação aos requisitos legais para composição dos conselhos de administração das companhias de capital aberto, a lei das sociedades por ações estabelece o mínimo de 3 conselheiros. Além disso, o IBGC (2015) orienta que haja 5 conselheiros, o que é cumprido por todas as empresas listadas no N1-GC. Quanto à formação de conselhos independentes, destaca-se a companhia OI do setor de telecomunicações, em que $85 \%$ do seu conselho de administração é formado por membros independentes. Destacam-se também as empresas de Siderurgia e Metalurgia Gerdau, Gerdau Metalúrgica e Usiminas, nas quais a participação de membros independentes supera os 40\%.

Além disso, é importante analisar a composição dos conselhos quanto à diversidade de conhecimentos e gênero, uma vez que o IBGC (2015, p. 42) estabelece que:

O conselho de administração deve ser composto tendo em vista a diversidade de conhecimentos, experiências, comportamentos, aspectos culturais, faixa etária e de gênero. Ele deve garantir que a diretoria estabeleça e divulgue políticas que propiciem igualdade de oportunidades para o acesso de mulheres a posições de alta liderança na organização.

Os resultados apontam uma forte disparidade de gênero entre os conselheiros (Tabela 2), pois, dos 221 conselheiros, apenas $15(6,8 \%)$ são do gênero feminino, sendo que 3 em uma única empresa. Essa proporção é ainda menor ao se excluir os conselheiros duplicados em board interlocking com as empresas 
da amostra. De um total de 199 conselheiros distintos, 13 são mulheres (6,5\%). Tal desigualdade também se evidencia ao se constatar que em somente 12 conselhos há a presença de mulheres, sendo os demais formados exclusivamente por homens.

Tabela 2 - Participação de mulheres nos conselhos

\begin{tabular}{lccc}
\hline \multicolumn{1}{c}{ Empresa } & Conselheiros & Número de Mulheres & Porcentagem Relativa \\
\hline COPEL & 9 & 3 & $33,3 \%$ \\
FERBASA & 9 & 2 & $22,2 \%$ \\
BRADESPAR & 6 & 1 & $16,7 \%$ \\
ITAUSA & 6 & 1 & $16,7 \%$ \\
LOJAS AMERIC & 6 & 1 & $16,7 \%$ \\
CEEE-GT & 6 & 1 & $16,7 \%$ \\
CEEE-D & 7 & 1 & $14,3 \%$ \\
BRADESCO & 9 & 1 & $11,1 \%$ \\
TRAN PAULIST & 9 & 1 & $11,1 \%$ \\
USIMINAS & 12 & 1 & $8,3 \%$ \\
BRASKEM & 13 & 1 & $7,7 \%$ \\
CEMIG & 15 & 1 & $6,7 \%$ \\
\hline
\end{tabular}

Fonte: Elaborado pelos autores (2019).

Os achados vão ao encontro de outras pesquisas que analisam a diversidade de gênero na composição dos conselhos de administração e também constatam a baixa participação feminina (FRAGA; SILVA, 2012; NISIYAMA; NAKAMURA, 2018). Apesar disso, Fraga e Silva (2012), em um levantamento efetuado com empresas listadas na bolsa de valores brasileira que não possuíam controle majoritário (aquelas com mais de 50\% do capital em circulação no mercado), identificaram que as empresas que possuíam mulheres em seus respectivos conselhos apresentavam um desempenho de mercado significativamente superior às demais. Resultado semelhante é apontado por Schmiliver et al. (2019), que identificam que a maior presença de mulheres nos CA cria valor à empresa e melhora seu desempenho financeiro.

Quanto às relações de parentesco, os dados indicam que 12 empresas possuem, na formação do seu conselho, a presença de algum familiar (Tabela 3). Ressalta-se que nesta pesquisa a relação de parentesco foi identificada unicamente pela uniformidade entre os nomes dos executivos. Nesse quesito, destaca-se a Cia Fiação Tecidos Cedro Cachoeira (CEDRO), com mais de 40\% de seu conselho formado por relações familiares, demonstrando que, apesar de ser uma empresa de capital aberto, possui características de uma organização familiar.

Tabela 3 - Relações de Parentesco nos Conselhos de Administração

\begin{tabular}{lccc}
\hline \multicolumn{1}{c}{ Empresa } & Conselheiros & Número de Familiares & Porcentagem Relativa \\
\hline CEDRO & 12 & 5 & $41,7 \%$ \\
ITAUUNIBANCO & 13 & 4 & $30,8 \%$ \\
GERDAU & 7 & 3 & $42,9 \%$ \\
GERDAU MET & 7 & 3 & $42,9 \%$ \\
ALPARGATAS & 7 & 2 & $28,6 \%$ \\
BRADESCO & 9 & 2 & $22,2 \%$ \\
BRADESPAR & 6 & 2 & $33,3 \%$ \\
EUCATEX & 7 & 2 & $28,6 \%$ \\
FRAS-LE & 6 & 2 & $33,3 \%$ \\
ITAUSA & 6 & 2 & $33,3 \%$ \\
LOJAS AMERIC & 6 & 2 & $33,3 \%$ \\
RANDON PART & 6 & 2 & $33,3 \%$ \\
\hline
\end{tabular}

Fonte: Elaborado pelos autores (2019).

Outro fator relevante citado na B3 e nos códigos do IBGC para as boas práticas de GC é a restrição aos acúmulos das funções de CEO e Chairman pelo mesmo executivo. O Quadro 1 contrapõe tais funções para cada empresa da amostra analisada. 
Fábio Pagliarini do Nascimento, Patrícia Saltorato, Tiago Fonseca Albuquerque Cavalcanti Sigahi e Geraldo Tessarini Junior

Quadro 1 - Chairmen/Vice-Chairmen e CEOs/Vice-CEOs das empresas listadas no N1-GC da B3

\begin{tabular}{|c|c|c|}
\hline Razão Social & Chairman/Vice-Chairman & CEOs/Vice-CEOs \\
\hline ALPARGATAS & Pedro Moreira Salles & Marcio Luiz Simões Utsch \\
\hline \multirow{2}{*}{ BANCO PAN } & Gilberto Magalhães Occhi & \multirow{2}{*}{ Luiz Francisco Monteiro de Barros Neto } \\
\hline & Sérgio Cutolo dos Santos & \\
\hline \multirow[b]{2}{*}{ BRADESCO } & Luiz Carlos Trabuco Cappi & Octavio de Lazari Junior \\
\hline & Carlos Alberto Rodrigues Guilherme & $\begin{array}{l}\text { Josué Augusto Pancini/Maurício Machado de } \\
\text { Minas }\end{array}$ \\
\hline \multirow{2}{*}{ BRADESPAR } & Lázaro de Mello Brandão & \multirow{2}{*}{ Fernando Jorge Buso Gomes } \\
\hline & Luiz Carlos Trabuco Cappi & \\
\hline \multirow{2}{*}{ BRASKEM } & Newton Sérgio de Souza & \multirow{2}{*}{ Fernando Musa } \\
\hline & Ernani Filgueiras de Carvalho & \\
\hline \multirow[b]{2}{*}{ CEDRO } & Fabiano Soares Nogueira & \multirow[b]{2}{*}{ Marco Antônio Branquinho Júnior } \\
\hline & $\begin{array}{l}\text { Breno Mattos de Magalhães } \\
\text { Mascarenhas }\end{array}$ & \\
\hline CEEE-D & Vera Inêz Salgueiro Lermen & Paulo de Tarso Gaspar Pinheiro Machado \\
\hline CEEE-GT & Vera Inêz Salgueiro Lermen & Paulo de Tarso Gaspar Pinheiro Machado \\
\hline \multirow{2}{*}{ CEMIG } & José Afonso Bicalho Beltrão da Silva & \multirow{2}{*}{ Bernardo Afonso Salomão de Alvarenga } \\
\hline & Marco Antônio de Rezende Teixeira & \\
\hline CESP & Ricardo Daruiz Borsari & Mauro Guilherme Jardim Arce \\
\hline COPEL & Mauricio Schulman & Jonel Nazareno Iurk \\
\hline ELETROBRAS & Jose Guimarães Monforte & Wilson Ferreira Júnior \\
\hline \multirow{2}{*}{ EUCATEX } & Otavio Maluf & Flavio Maluf \\
\hline & Flavio Maluf & Otavio Maluf \\
\hline \multirow{2}{*}{ FERBASA } & Bárbara Klein de Araújo Carvalho & \multirow{2}{*}{ Marcio Lopes Fernandes de Barros } \\
\hline & Geraldo de Oliveira Lopes & \\
\hline \multirow{2}{*}{ FRAS-LE } & David Abramo Randon & \multirow{2}{*}{ Sergio Lisbão Moreira de Carvalho } \\
\hline & Astor Milton Schmitt & \\
\hline GERDAU & Claudio Johannpeter & Gustavo Werneck da Cunha \\
\hline GERDAU MET & Claudio Johannpeter & Gustavo Werneck da Cunha \\
\hline \multirow{3}{*}{ ITAUSA } & Henri Penchas & \multirow{2}{*}{ Alfredo Egydio Setubal } \\
\hline & Ana Lúcia de Mattos Barretto Villela & \\
\hline & Alfredo Egydio Setubal & Rodolfo Villela Marino \\
\hline \multirow{2}{*}{ ITAUUNIBANCO } & Pedro Moreira Salles ${ }^{\mathrm{a}}$ & \multirow{2}{*}{ Candido Botelho Bracher } \\
\hline & Roberto Egydio Setubal $^{\mathrm{a}}$ & \\
\hline LOJAS AMERIC & Carlos Alberto da Veiga Sicupira & Miguel Gomes Pereira Sarmiento Gutierrez \\
\hline \multirow{2}{*}{ OI } & José Mauro Mettrau Carneiro da Cunha & \multirow{2}{*}{ Eurico de Jesus Teles Neto } \\
\hline & Ricardo Reisen de Pinho & \\
\hline \multirow[b]{2}{*}{ P.ACUCAR-CBD } & Jean-Charles Henri Naouri & \multirow[b]{2}{*}{ Ronaldo Iabrudi dos Santos Pereira } \\
\hline & $\begin{array}{l}\text { Arnaud Daniel Charles Walter Joachim } \\
\text { Strasser }\end{array}$ & \\
\hline \multirow{2}{*}{ RANDON PART } & Alexandre Randon & \multirow{2}{*}{ David Abramo Randon } \\
\hline & Hugo Eurico Irigoyen Ferreira & \\
\hline \multirow{2}{*}{ TRAN PAULIST } & Bernardo Vargas Gibsone & \\
\hline & Gustavo Carlos Marin Garat & Reynaldo Passanez1 Filho \\
\hline USIMINAS & Elias de Matos Brito & Sergio Leite de Andrade \\
\hline
\end{tabular}

Fonte: Elaborado pelos autores (2019). Nota: ${ }^{\text {a}}$ Copresidente do Conselho de Administração.

É interessante observar a formação da mais alta gerência nos conselhos da Eucatex, Gerdau e Metalúrgica Gerdau S.A. Quanto à primeira, observa-se que o seu CEO é, concomitantemente, o Vice-Chairman da companhia, enquanto o presidente do conselho de administração (Chairman) é também Vice-Presidente da empresa. Isso ocorre de forma semelhante na Itausa, onde o CEO é também Vice-Chairman. Em relação às duas últimas, nota-se que as mesmas pessoas exercem o cargo de CEO e Chairman em ambas.

Conforme disposto pelo regulamento da B3 e na CVM, há uma restrição quanto ao acúmulo das posições de CEO e Chairman pelo mesmo membro executivo. Nesse sentido, é válida a discussão sobre a 
composição das quatro posições-chave em conselhos como da Eucatex, na qual tais funções são ocupadas por apenas dois executivos. Apesar de a exigência disposta ser atendida, é possível levantar a hipótese de que a ocupação desses cargos, da forma como se encontram, são apenas artifícios para o cumprimento das regras. Essa mesma hipótese pode ser considerada para o conselho da Randon, visto que há a ocupação dos cargos de CEO e Chairman por parentes.

Outro ponto a ser destacado é a formação acadêmica dos executivos. Foi possível levantar essa informação para $188(94,5 \%)$ dos profissionais pesquisados, conforme demonstrado na Figura 1.

Figura 1 - Formação acadêmica dos conselheiros

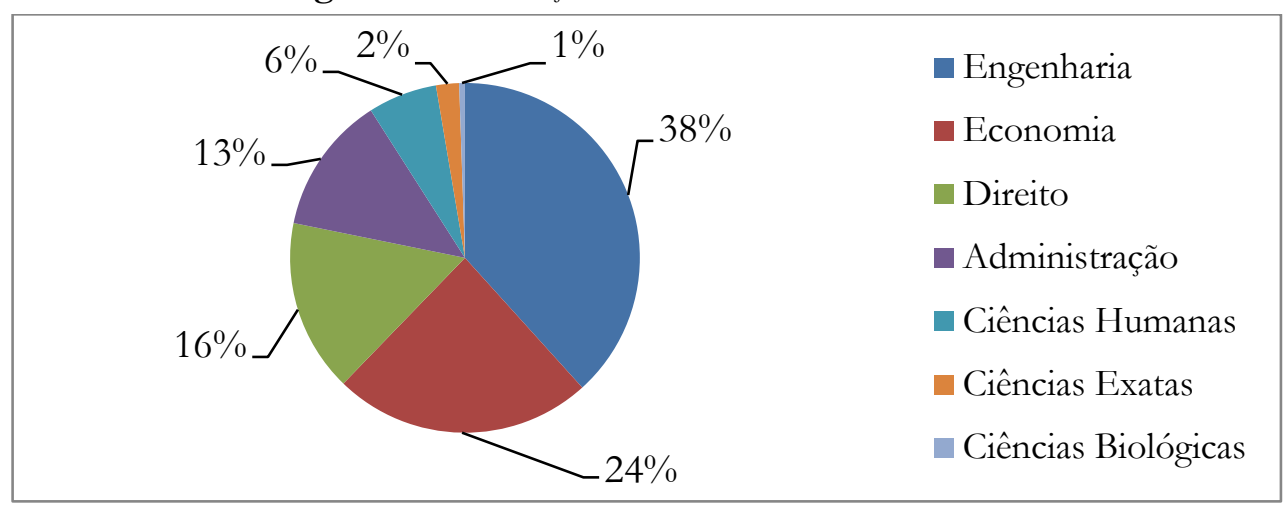

Fonte: Elaborado pelos autores (2019).

Constata-se que mais de 60\% dos 188 conselheiros possuem formação, em nível de graduação, nas áreas de Engenharia e Economia, compondo-se o restante principalmente pelas áreas de Direito e Administração. Em uma análise genérica - e não especificamente em cada conselho - é possível afirmar que não há uma aderência significativa à recomendação de que o conselho de administração deve possuir diversidade de conhecimentos em sua composição IBCG (2015). Contudo, Fraga e Silva (2012) identificaram em seu estudo que enquanto a maior diversidade nos anos de escolaridade tem efeito positivo no desempenho organizacional, a diversidade nas áreas de formação tem efeito negativo, o que pode ser explicado, em parte, pela existência de conselheiros com formação acadêmica pouco contributiva para o entendimento dos negócios da empresa em que atuam.

Quanto às instituições de ensino onde os executivos se formaram, nota-se que, apesar da constatação de 58 diferentes instituições, há uma concentração em apenas cinco universidades, quais sejam: USP (10,9\%), PUC (10,2\%), UFRJ (7,8\%), UFMG (6,3\%) e FGV (5,5\%). Em relação à pós-graduação, foi identificado que $49,7 \%$ dos executivos concluíram algum curso de especialização, MBA, mestrado ou doutorado. Destes, 50,5\% concluíram o curso no exterior, especialmente na Universidade de Harvard.

\section{Board interlocking entre conselheiros do Nível 1 de Governança Corporativa da B3}

Ao classificar todos os 199 diferentes conselheiros, notou-se que 83 (41,7\%) deles se encontram em situação de board interlocking; isto é, compõem mais de um conselho de administração. Com relação aos conselheiros independentes, 23 dos 39 conselheiros independentes distintos constituem relações interconectadas, correspondendo a 52,3\%. A Tabela 4 apresenta o grau de board interlocking para cada empresa da amostra, o total de relações de BI de cada conselho e as suas conexões. 
Fábio Pagliarini do Nascimento, Patrícia Saltorato, Tiago Fonseca Albuquerque Cavalcanti Sigahi e Geraldo Tessarini Junior

Tabela 4 - Conselheiros em situação de BI por conselho/empresa

\begin{tabular}{|c|c|c|c|c|c|c|}
\hline Nome Empresa & $\begin{array}{c}\text { Total de } \\
\text { Conselheiros }\end{array}$ & $\begin{array}{c}\text { Conselheiros } \\
\text { em BI }\end{array}$ & $\begin{array}{c}\% \% \\
\text { Conselheiros } \\
\text { em BI por } \\
\text { conselho }\end{array}$ & $\begin{array}{l}\text { Número de } \\
\text { conselhos em } \\
\text { BI por } \\
\text { conselho }\end{array}$ & $\begin{array}{l}\text { Conexões } \\
\text { por } \\
\text { conselho }\end{array}$ & $\begin{array}{l}\text { Média de } \\
\text { conexões } \\
\text { por } \\
\text { conselheiro }\end{array}$ \\
\hline ALPARGATAS & 7 & 6 & $85,7 \%$ & 26 & 212 & 30,3 \\
\hline BANCO PAN & 15 & 10 & $66,7 \%$ & 15 & 214 & 14,3 \\
\hline BRADESCO & 9 & 3 & $33,3 \%$ & 10 & 163 & 18,1 \\
\hline BRADESPAR & 6 & 5 & $83,3 \%$ & 13 & 129 & 21,5 \\
\hline BRASKEM & 13 & 4 & $30,8 \%$ & 12 & 285 & 21,9 \\
\hline CEDRO & 12 & 0 & $0,0 \%$ & 0 & 77 & 6,4 \\
\hline CEEE-D & 7 & 5 & $71,4 \%$ & 20 & 100 & 14,3 \\
\hline CEEE-GT & 6 & 5 & $83,3 \%$ & 20 & 100 & 16,7 \\
\hline CEMIG & 15 & 4 & $26,7 \%$ & 13 & 691 & 46,1 \\
\hline CESP & 7 & 1 & $14,3 \%$ & 5 & 118 & 16,9 \\
\hline COPEL & 9 & 1 & $11,1 \%$ & 2 & 122 & 13,6 \\
\hline ELETROBRAS & 9 & 6 & $66,7 \%$ & 12 & 241 & 26,8 \\
\hline EUCATEX & 7 & 0 & $0,0 \%$ & 0 & 42 & 6,0 \\
\hline FERBASA & 9 & 1 & $11,1 \%$ & 1 & 63 & 7,0 \\
\hline FRAS-LE & 6 & 4 & $66,7 \%$ & 8 & 54 & 9,0 \\
\hline GERDAU & 7 & 6 & $85,7 \%$ & 9 & 146 & 20,9 \\
\hline GERDAU MET & 7 & 6 & $85,7 \%$ & 8 & 126 & 18,0 \\
\hline ITAUSA & 6 & 6 & $100,0 \%$ & 17 & 170 & 28,3 \\
\hline ITAUUNIBANCO & 13 & 7 & $53,8 \%$ & 25 & 349 & 26,8 \\
\hline LOJAS AMERIC & 6 & 4 & $66,7 \%$ & 11 & 207 & 34,5 \\
\hline $\mathrm{OI}$ & 7 & 5 & $71,4 \%$ & 12 & 228 & 32,6 \\
\hline P.ACUCAR-CBD & 11 & 8 & $72,7 \%$ & 21 & 379 & 34,5 \\
\hline RANDON PART & 6 & 1 & $16,7 \%$ & 2 & 19 & 3,2 \\
\hline TRAN PAULIST & 9 & 4 & $44,4 \%$ & 16 & 173 & 19,2 \\
\hline USIMINAS & 12 & 3 & $25,0 \%$ & 8 & 281 & 23,4 \\
\hline- & 221 & 105 & $47,5 \%$ & 286 & 4689 & 23,4 \\
\hline
\end{tabular}

Fonte: Elaborado pelos autores (2019).

Conforme a análise dos dados, destaca-se o conselho da Itausa, onde 100\% dos seus conselheiros participam de outro(s) conselhos. Outras 5 empresas possuem um grau de interlocking em seus conselhos de mais de $80 \%$. Por outro lado, companhias como a Eucatex e Cedro distinguem-se por não terem nenhum conselheiro em BI. Outro dado importante revela que algumas empresas concretizam uma relação de BI por meio de seus conselheiros com 20 ou mais conselhos, entre elas, Itaú, Alpargatas, Grupo Pão de Açúcar, Cedrp e CEEE-D. Entretanto, uma limitação a ser apontada, é que este dado não descreve exatamente com quantos conselhos distintos as empresas estão relacionadas, pois existe a possibilidade de que dois ou mais conselheiros diferentes da mesma companhia possam ter, dentro de suas relações de interlocking, uma rede semelhante. É o que ocorre, por exemplo, com os conselheiros Marco A. Crespi Bonomi e Pedro Moreira Salles que são ambos conselheiros do Itaú Unibanco e da Porto Seguro S.A.

Foi identificado também, através de consulta ao sítio da imprensa de negócios Bloomberg, o número de conexões de cada conselho. Esse valor é estabelecido pela soma do número de conexões individuais de cada conselheiro. Por exemplo, nos casos em que o conselheiro atua em uma única companhia, o seu número de conexões será o número de executivos daquele conselho menos ele próprio. Dessa maneira, conforme a definição da Bloomberg, as conexões estão relacionadas ao número de pessoas com quem um determinado executivo interage.

A Tabela 5 descreve os 10 conselheiros com maior número de conexões. Vale ressaltar que, durante a coleta de dados, nem todos os conselheiros pesquisados possuíam o número de conexões que realizavam disponível. 
Tabela 5 - Conselheiros da amostra com maior número de conexões

\begin{tabular}{lc}
\hline \multicolumn{1}{c}{ Nome } & Conexões \\
\hline José Pais Rangel & 100 \\
José Mauro Mettrau Carneiro da Cunha & 86 \\
Jean-Charles Henri Naouri & 86 \\
Marco Antônio de Rezende Teixeira & 84 \\
Marcelo Gasparino da Silva & 75 \\
Nélson José Hubner Moreira & 72 \\
José Afonso Bicalho Beltrão da Silva & 62 \\
Pedro Moreira Salles & 60 \\
Bernardo Vargas Gibsone & 55 \\
Marco Antônio Soares Castelo Branco & 54 \\
\hline
\end{tabular}

Fonte: Elaborado pelos autores (2019).

O board interlocking não acontece de forma efetiva entre as empresas pesquisadas, mas interconectando as outras empresas em geral, sejam elas nacionais ou estrangeiras, listadas em diferentes segmentos da B3 e ainda as não listadas. Considerando os 199 conselheiros da amostra, foi possível identificar 198 empresas em board interlocking. A fim de esclarecer como se dá esse fenômeno, a Figura 2 exemplifica uma das principais redes de BI identificadas na pesquisa, a qual possui 42 empresas envolvidas direta ou indiretamente, das quais somente as companhias Alpargatas, Itausa e Itaú estão listadas no nível 1 de GC.

Figura 2 - Representação da Rede I

Companhias da amostra ou conectadas a mais de um conjuntos de atores

Conselheiro intermediador da conexao

Conexão direta

- - Conexão direta, porém há o cruzamento de linhas.
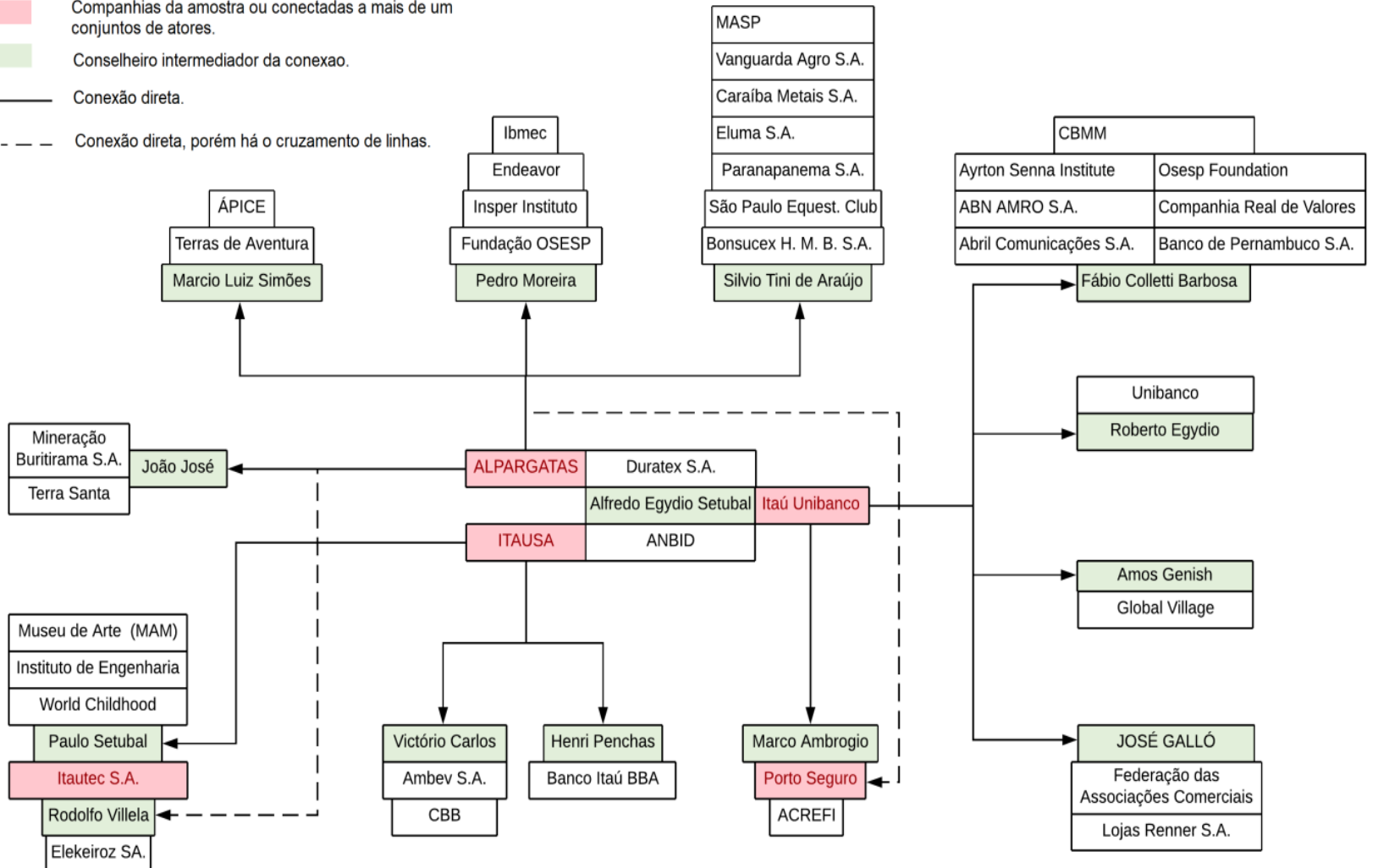

Fonte: Elaborado pelos autores (2019).

As empresas destacadas em vermelho são as que possuem maior representatividade na rede, pois são responsáveis por conectar mais de um grupo de empresas. Considera-se como grupo, neste estudo, o conjunto de organizações conectadas pelo mesmo executivo. Por exemplo, a empresa Alpargatas possui uma conexão direta (ou de primeiro grau) com 6 grupos de organizações distintas, intermediada pelos seus conselheiros Alfredo Egydio, Silvio Tini, Pedro Moreira, Marcio Luiz, João José, Marco Ambrogio 
e Rodolfo Villela. É possível afirmar, ainda, que tal companhia tem uma relação indireta (ou de segundo grau) com as organizações World Childhood, o Instituto de Engenharia e o Museu de Arte (MAM) por meio da relação do Rodolfo Villela (conselheiro da Alpargatas e Itautec S.A) com Paulo Setubal (conselheiro da Itautec S. A. e das organizações citadas). Outra consideração interessante é o board interlocking formado entre a Itausa e a Itautec S.A., onde a conectividade se dá por meio de conselheiros com um possível grau de parentesco.

\section{Análise das redes sociais de board interlocking entre conselheiros}

Ao examinar as 198 organizações distintas em estado de board interlocking, pela conectividade dos 199 conselheiros, foram identificadas 12 redes que agregam todas as empresas em BI. Vale ressaltar que nem todas as redes possuem ramificações com relações indiretas, ou seja, algumas dessas redes apenas possuem uma única organização central, com conexões unicamente de primeiro grau. $O$ grafo apresentado na Figura 3 representa uma caracterização das diferentes redes formadas no N1-GC.

Figura 3 - Representação unificada das redes no N1-GC

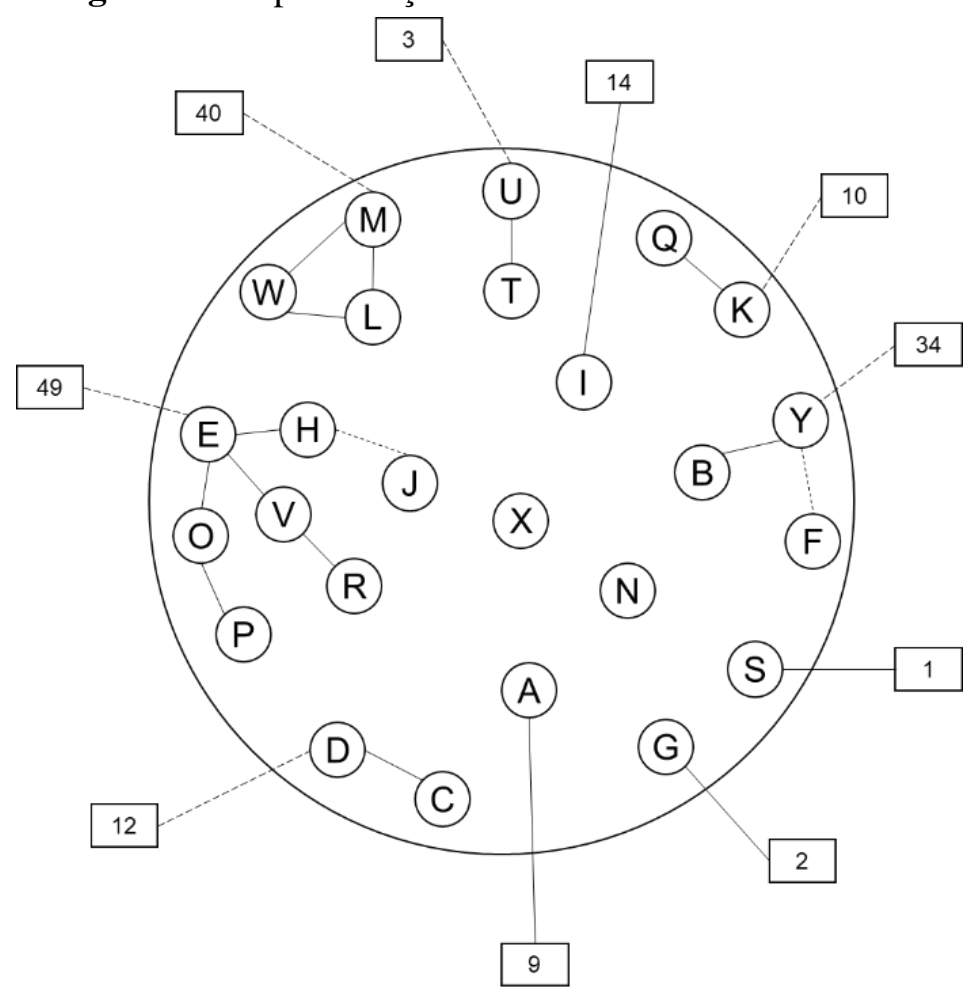

Fonte: Elaborado pelos autores (2019).

As empresas listadas no N1-GC estão contidas graficamente na região interna do círculo. As linhas contínuas evidenciam as conexões diretas entre as companhias. Por outro lado, as linhas tracejadas representam conexões indiretas, contendo uma organização intermediária entre a ligação. Os números na parte externa do círculo retratam a quantidade de organizações listadas em outros segmentos (ou não listadas) que estão conectadas à rede.

Com o objetivo de entender a influência de cada uma dessas empresas em um contexto geral, foi calculada a centralidade de grau para cada uma das organizações da amostra, considerando como o número total de relações possíveis, as 25 empresas no segmento do estudado. 
A centralidade de grau auxilia a compreensão de um determinado nó (empresa/conselho) em uma rede social, através da identificação dos nós que possuem o maior número de ligações na rede. Segundo Chelmis e Prasanna (2011), o seu cálculo se dá pela seguinte equação:

$$
C G(i)=\frac{\sum_{j=1}^{n} a(i, j)}{n-1}, \text { onde: }
$$

- $C G(i)$ é o grau de centralidade no nó de interesse;

- né o número de nós;

- $a(i, j)$ é a variável que indica se existe conexão entre os nós $i$ e $j$.

O cálculo do grau de centralidade se deu pelo total de relações de interlocking de cada empresa da amostra sobre o total de empresas listadas no N1-GC. Os resultados estão contidos na Tabela 6.

Tabela 6 - Grau de centralidade dos conselhos de administração das empresas do N1-GC da B3

\begin{tabular}{ccccc}
\hline Empresa & Nome Empresa & Setor & $\begin{array}{c}\mathbf{N}^{\mathbf{o}} \text { de } \\
\text { interlocking } \\
\text { entre Amostra }\end{array}$ & $\begin{array}{c}\text { Centralidade de } \\
\text { Grau }\end{array}$ \\
\hline E & CEMIG & Energia Elétrica & 3 & 0,1250 \\
W & ALPARGATAS & Tecidos, Vestuário e Calçados & 2 & 0,0833 \\
O & FRAS-LE & Material de Transporte & 2 & 0,0833 \\
L & ITAUSA & Intermediários Financeiros & 2 & 0,0833 \\
M & ITAUUNIBANCO & Intermediários Financeiros & 2 & 0,0833 \\
V & USIMINAS & Siderurgia e Metalurgia & 2 & 0,0833 \\
K & BRADESCO & Intermediários Financeiros & 1 & 0,0417 \\
Q & BRADESPAR & Mineração & 1 & 0,0417 \\
R & BRASKEM & Químicos & 1 & 0,0417 \\
C & CEEE-D & Energia Elétrica & 1 & 0,0417 \\
D & CEEE-GT & Energia Elétrica & 1 & 0,0417 \\
H & ELETROBRAS & Energia Elétrica & 1 & 0,0417 \\
T & GERDAU & Siderurgia e Metalurgia & 1 & 0,0417 \\
U & GERDAU MET & Siderurgia e Metalurgia & 1 & 0,0417 \\
Y & OI & Telecomunicações & 1 & 0,0417 \\
B & P.ACUCAR-CBD & Comércio e Distribuição & 1 & 0,0417 \\
P & RANDON PART & Material de Transporte & 1 & 0,0000 \\
J & BANCO PAN & Intermediários Financeiros & 0 & 0,0000 \\
X & CEDRO & Tecidos, Vestuário e Calçados & 0 & 0,0000 \\
F & CESP & Energia Elétrica & 0 & 0,0000 \\
G & COPEL & Energia Elétrica & 0,0000 \\
N & EUCATEX & Madeira e Papel & 0,0000 \\
S & FERBASA & Siderurgia e Metalurgia & 0,0000 \\
A & LOJAS AMERIC & Comércio & 0 & 0,0000 \\
I & TRAN PAULIST & Energia Elétrica & 0 & 0 \\
\hline & & 0 & & \\
\hline
\end{tabular}

Fonte: Elaborado pelos autores (2019).

A avaliação do grafo revela que, apesar de $92 \%$ das empresas pesquisadas praticarem o board interlocking através da atuação em múltiplos conselhos de $42 \%$ dos conselheiros, essa conectividade não se dá efetivamente de forma interna ao N1-GC, mas com organizações externas. Pelo lado dos conselheiros, isso significa que a sua atuação em outros conselhos de administração ocorre prioritariamente em empresas listadas em outros segmentos de Governança Corporativa da B3 (ou sem listagem). Essa observação é confirmada pelo baixo grau de centralidade das empresas da amostra, bem abaixo de 1, indicando que existem poucas ligações entre essas companhias, não existindo um nó central que conecta de forma simultânea diversas empresas listadas neste segmento. Ressalta-se que essa conclusão se dá ao avaliar as empresas como um todo e considerando cada agente da amostra como uma possibilidade de ligação. 
A partir do mesmo tipo de análise quantitativa, porém agora com foco em uma rede única (sem fragmentações) e considerando as possibilidades de relações com todas as empresas dessa rede (não apenas as empresas da amostra), foram determinadas as centralidades para a rede representada na Figura 4, a qual se configura como a principal rede identificada neste estudo em termos de quantitativo de organizações entrelaçadas de forma direta e indireta.

Figura 4 - Representação da Rede II com detalhamento de determinados conselheiros em BI

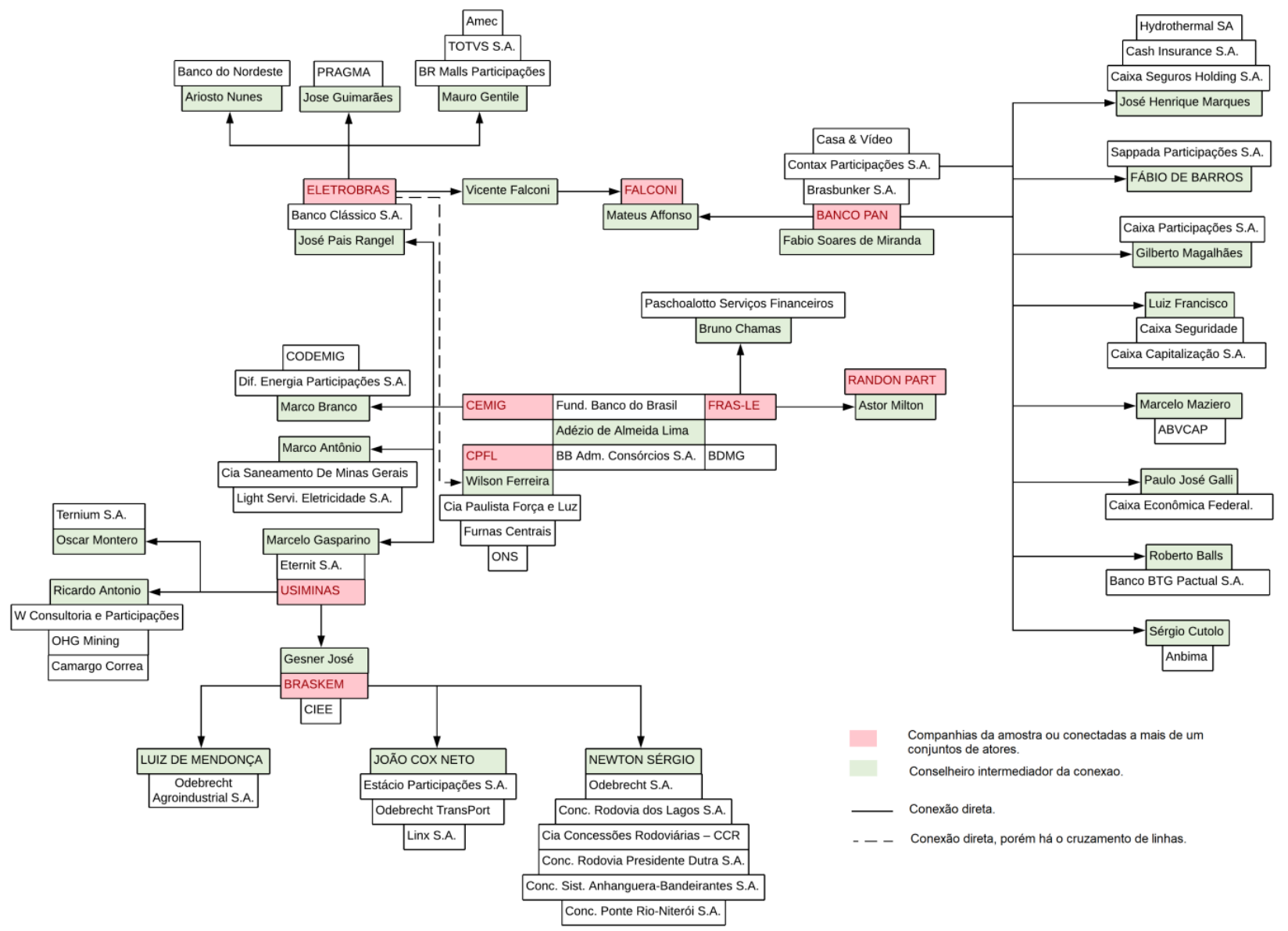

Fonte: Elaborado pelos autores (2019).

Os resultados mais relevantes estão descritos na Tabela 7, enquanto os resultados completos constam do Apêndice A. Considerando os índices de centralidade de grau, o Banco Pan se revela como a companhia com o maior grau, ou seja, possui a maior quantidade de ligações diretas com as organizações e, consequentemente, o maior grau de centralidade na rede em questão. Nesse sentido, o Banco Pan é a organização com o maior potencial de comunicação direta com outras, o que pode beneficiá-lo com informações vantajosas no mercado competitivo.

Tabela 7 - Métricas de Centralidade Rede II

\begin{tabular}{lccccc}
\hline \multicolumn{1}{c}{ Empresa } & Id & Grau & $\begin{array}{c}\text { Centralidade } \\
\text { de Grau }\end{array}$ & $\begin{array}{c}\text { Centralidade de } \\
\text { Intermediação }\end{array}$ & $\begin{array}{c}\text { Centralidade de } \\
\text { Proximidade }\end{array}$ \\
\hline BANCO PAN & 1 & 15 & 0,2727 & 658,0 & 0,2895 \\
CEMIG & 3 & 13 & 0,2364 & 874,5 & 0,4044 \\
ELETROBRAS & 4 & 12 & 0,2182 & 839,0 & 0,3929 \\
BRASKEM & 2 & 12 & 0,2182 & 477,0 & 0,2895 \\
CPFL Geração de Energia S/A & 36 & 9 & 0,1636 & 118,5 & 0,3526 \\
USIMINAS & 7 & 8 & 0,1455 & 675,0 & 0,3503 \\
FRAS-LE & 5 & 7 & 0,1273 & 107,0 & 0,3073 \\
\hline
\end{tabular}

Fonte: Elaborado pelos autores (2019). 
Entretanto, ao fazer uma análise visual da rede, conforme a Figura 5, podemos identificar que mesmo não sendo a companhia com o maior grau de centralidade entre as empresas da amostra, a Cemig possui influência de comunicação e intermediação na rede maior que todas as outras organizações, visto que é através dela que se dá a comunicação indireta da maioria das companhias. Essa análise é comprovada através da Centralidade de Intermediação (betweenness centrality), que quantifica quando um determinado nó aparece no caminho geodésico (o caminho mais curto) entre dois nós da rede. Assim, ela identifica o quão "ponte" é um determinado nó pelo número de caminhos entre as conexões que precisam passar pelo nó entre os vários grupos (FREEMAN, 1978).

Nesse aspecto, companhias como Cemig, Eletrobrás e Usiminas possuem maior relevância e influência dentro da Rede II do que o Banco Pan, de modo que a maior parte dos demais nós ao compartilharem informações com os outros agentes, dentro do conceito de redes, necessitam do auxílio de tais companhias.

O conceito de centralidade de proximidade, descrito por Chelmis e Prasanna (2011), em que se mede o comprimento médio dos caminhos mais curtos (pela quantidade de arestas) de um nó para cada um dos outros nós, permite compreender o alcance que um determinado agente possui na rede. Seu cálculo se dá pela seguinte equação:

$$
C p(i)=\frac{n-1}{\sum_{j=1}^{n} e(i, j)} \text {, onde: }
$$

- Cp(i) é a centralidade de proximidade do nó de interesse;

- né o número de nós;

- $e(i, j)$ é o número de arestas no caminho mais curto do nó $i$ para o nó $j$.

Assim como na centralidade de intermediação, a Cemig também é a principal empresa nesse quesito, reforçando ainda mais a sua importância na rede em questão, pois além de ser a segunda companhia com maior quantidade de conexões diretas, possui o maior potencial de intermediação na rede e a maior proximidade média com todos os agentes. Por outro lado, o Banco Pan, apesar de ter o maior grau e um relativo potencial de intermediação, é apenas a $19^{\mathrm{a}}$ empresa neste aspecto (Apêndice A). Em termos práticos, isso significa que se o Banco Pan sair desta rede, levando consigo apenas as empresas que estão ligadas unicamente a ele, ainda assim a maior parte das ramificações seria mantida e a rede se dividiria em duas redes independentes. Por outro lado, caso a Cemig deixasse de ser um agente integrante, juntamente com as organizações conectadas somente a ela, a rede se fragmentaria em 3 grupos distintos, conforme demonstrado na Figura 5.

Figura 5 - Grafo da Rede II com saída da Cemig e relacionadas

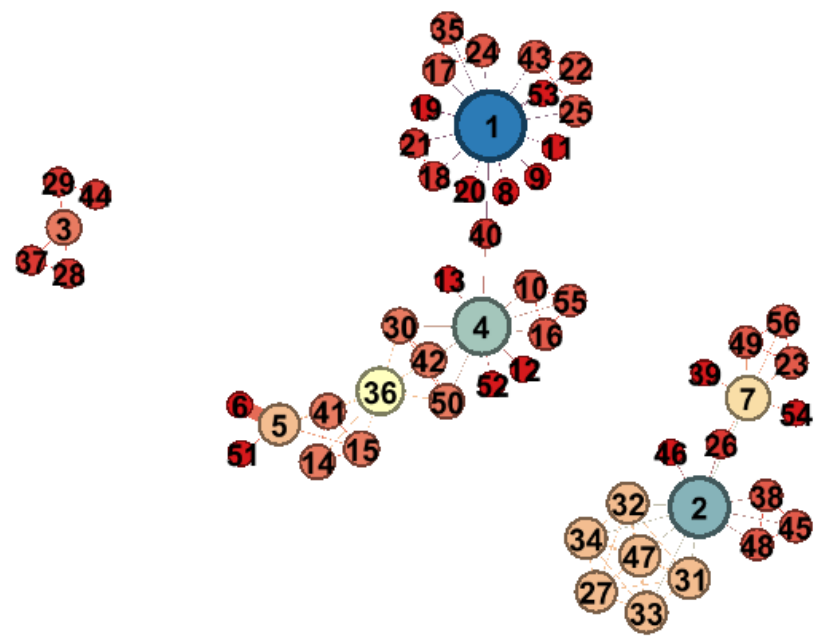

Fonte: Elaborado pelos autores (2019). 
A Figura 6 permite a comparação das organizações da Rede II quanto aos conceitos de grau e de intermediação, de forma que à esquerda os agentes com maior grau são destacados por dimensão e em escala do azul para o vermelho (de maior ao menor grau respectivamente). De maneira semelhante, à direita é apresentada a mesma rede, porém com destaques (em dimensão e cor) aos nós de maior centralidade de intermediação. Assim como ocorre na Figura 5, os números indicados representam o número de identificação (Id) de cada companhia, conforme detalhamento contido no Apêndice A.

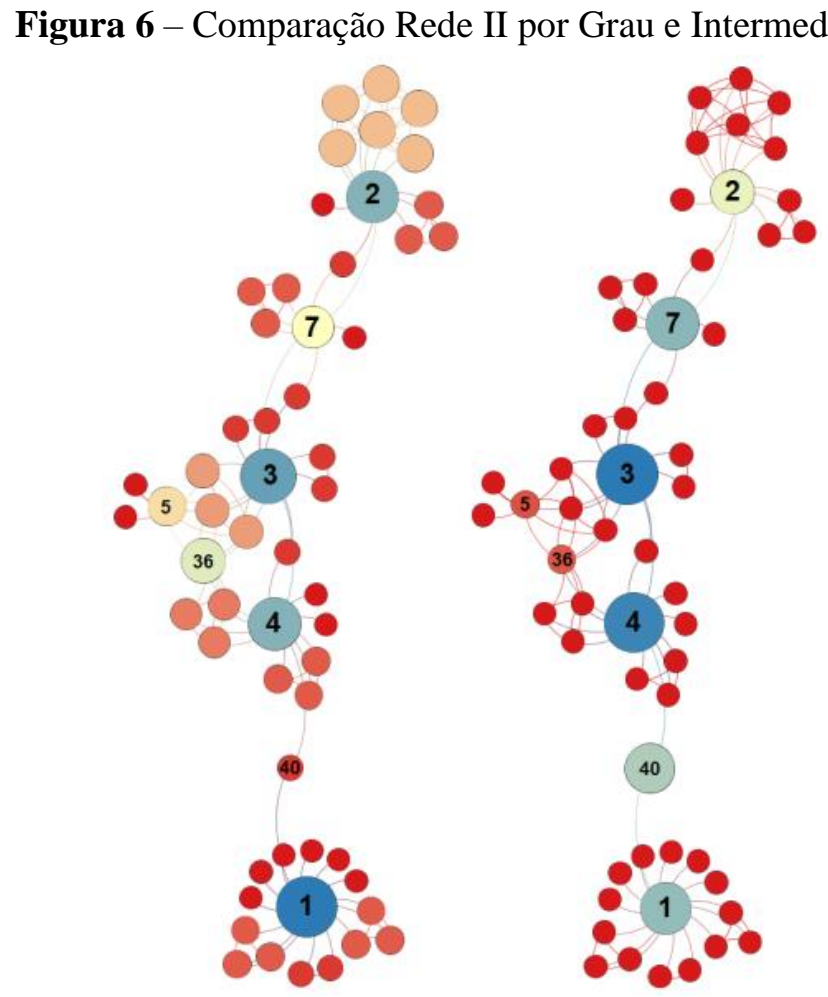

Fonte: Elaborado pelos autores (2019).

\section{Considerações finais}

Neste estudo, buscou-se analisar a formação do board interlocking no âmbito das empresas listadas no Nível 1 de Governança Corporativa da Bolsa de Valores do Brasil (B3), de forma a preencher uma lacuna de pesquisas, sob essa perspectiva, no cenário nacional. A principal contribuição deste estudo se dá, portanto, ao oferecer um retrato do BI no segmento analisado, o que permite a ampliação das discussões acadêmicas sobre o tema, bem como pode ser relevante aos gestores e acionistas na compreensão da ocorrência do BI nas empresas brasileiras, levando, com isso, à tomada de decisões de forma mais assertiva.

Os resultados apontaram que $42 \%$ dos conselheiros pesquisados atuam de forma simultânea em mais de um conselho de administração e que $92 \%$ das empresas listadas possuem interlocking com outras organizações por meio de um ou mais de seus executivos. Esse resultado demonstra certo equilíbrio nos CA do segmento estudado, o que pode ser considerado uma medida estratégica na condução dos negócios. Isso porque, por um lado, as empresas podem se beneficiar com o compartilhamento de experiências e informações entre os conselheiros presentes em uma rede de contatos de interlocking, o que pode fundamentar a determinação de estratégias e inovações. Por outro lado, a fração de conselheiros que não pratica o BI pode ser vista como fundamental para proporcionar maior segurança na defesa dos interesses dos investidores, já que, teoricamente, possuem maior tempo de dedicação a uma só empresa. 
Quanto à composição de conselheiros independentes - fator não obrigatório no N1-GC - destaca-se uma variação entre os conselhos que vai de $0 \%$ a $85 \%$. A literatura aponta que quanto maior o quantitativo de conselheiros independentes, maior será a probabilidade de uma atuação mais técnica, com maior isenção emocional e financeira, ou seja, maior objetividade perante os interesses da organização.

Os resultados apontaram ainda que os requisitos legais como a quantidade mínima de conselheiros e a restrição ao acúmulo dos cargos de CEO e Chairman foram atendidas por todas as empresas listadas. Ainda assim, algumas hipóteses podem ser levantadas quanto à imparcialidade nas decisões, visto que uma das companhias possui os dois cargos ocupados por executivos com grau de parentesco. No mesmo sentido, algumas organizações possuem os cargos de CEO e vice-presidência do CA ocupados pela mesma pessoa. Revela-se, também, quanto à composição dos conselhos, a inadequação das companhias às orientações de diversidade de gênero e conhecimento.

Sobre a análise de redes, o diagnóstico dos agentes integrantes das redes através da centralidade de grau demonstrou ser insuficiente para o real entendimento da influência de comunicação que cada agente possui e consequentemente ao acesso e compartilhamento de informações, o que representa uma limitação desta pesquisa. Além disso, a capacidade de intermediação dos nós possui grande importância na manutenção das conexões dos grupos, portanto, para a configuração das redes. É possível dizer que organizações com maior capacidade de intermediação não possuem apenas maior acesso a informações privilegiadas, mas também um maior poder de coesão em um mercado competitivo.

Esta pesquisa possui limitações quanto ao número de empresas analisadas e ao horizonte temporal considerado, visto que é possível que tenham ocorridas mudanças na composição dos conselhos analisados após o encerramento da coleta dos dados. Considerando tais limitações, entende-se oportuno, como sugestão para pesquisas futuras, que os estudos adotem perspectiva longitudinal, analisando as mudanças ocorridas ao longo dos anos na composição dos CA e como elas podem, de alguma maneira, afetar o desempenho organizacional a partir de múltiplas variáveis, como lucros, participação de mercado, criação de valor aos acionistas, entre outras. Também é importante a análise do BI em outros segmentos da B3, de forma a propiciar estudos comparativos que permitam investigações mais profundas sobre os efeitos do BI na gestão das empresas brasileiras. Ainda nesse sentido, não menos importante será a análise comparativa entre o BI no Brasil e em outros países, desenvolvidos ou não, aspecto ainda pouco explorado na literatura acadêmica. Finalmente, novos estudos, inclusive com métodos de coleta e análise predominantemente qualitativos e interpretativos, podem ser fundamentais para compreender os significados e os resultados concretos de diversos aspectos que tangem aos membros dos CA, tais como formação acadêmica, gênero, experiências anteriores e outros.

\section{Referências}

ASSUNÇÃO, R. R.; DE LUCA, M. M. M.; VASCONCELOS, A. C. Complexidade e governança corporativa: uma análise das empresas listadas na BM\&FBOVESPA. Revista de Contabilidade $\&$ Finanças, v. 28, n. 74, p. 213-228, 2017.

BEUREN, I. M.; DANI, A. C.; BECK, F. Relação entre as práticas do board interlocking e características de empresas de estrutura de propriedade familiar com ações mais negociadas na BM\&FBOVESPA. Revista Eletrônica de Ciência Administrativa, v. 13, n. 3, p. 339-355, 2014.

BLOOMBERG. Company Overview. Disponível em: https://www.bloomberg.com/markets/stocks. Acesso em: jun. 2018. 
Fábio Pagliarini do Nascimento, Patrícia Saltorato, Tiago Fonseca Albuquerque Cavalcanti Sigahi e Geraldo Tessarini Junior

BM\&FBOVESPA. Segmentos de listagem. Disponível em: $<$ http://www.bmfbovespa.com.br/pt_br/listagem/acoes/segmentos-de-listagem/sobre-segmentosde-listagem/>. Acesso em: fev. 2018.

BM\&FBOVESPA. Regulamento de listagem do nível 1 de governança corporativa, 2011. Disponível em: <http://www.b3.com.br/data/files/80/52/D8/7C/EEF606107D0F9606790D8AA8/Regulamentode-Listagem-aplicacao-Sancoes-Pecuniarias-Nivel-1.pdf.> Acesso em: set. 2018.

BM\&FBOVESPA. Regulamento de listagem do nível 2 de governança corporativa, 2011. Disponível em: <http://www.b3.com.br/data/files/1B/B5/A5/87/46E3861012FFCD76AC094EA8/Regulamento\% 20de $\% 20$ Listagem $\% 20 \mathrm{do} \% 20 \mathrm{~N} \% \mathrm{C} 3 \%$ ADvel $\% 202 \% 20(\mathrm{San} \% \mathrm{C} 3 \% \mathrm{~A} 7 \% \mathrm{C} 3 \% \mathrm{~B} 5 \mathrm{es} \% 202019)$.pdf.> Acesso em: set. 2018.

BORGATTI, S. P. 2-Mode concepts in social network analysis. In Meyers R. A. (Ed.) Encyclopedia of Complexity and System Science, v. 6, 2009, p. 8279-8291.

BRASIL. Lei n. 10.303, de 31 de outubro de 2001. Altera e acrescenta dispositivos na Lei $\mathbf{n}^{\mathbf{0}} \mathbf{6 . 4 0 4}$, de 15 de dezembro de 1976, que dispõe sobre as Sociedades por Ações, e na Lei ${ }^{\circ}$ 6.385, de 7 de dezembro de 1976, que dispõe sobre o mercado de Valores mobiliários e cria a Comissão de Valores Mobiliários. Disponível em: whttp://www.planalto.gov.br/ccivil_03/LEIS/L6404consol.htm. Acesso em: set. 2018.

CHELMIS, C.; PRASANNA, V. K. Social networking analysis: A state of the art and the effect of semantics. In: 2011 IEEE Third International Conference on Privacy, Security, Risk and Trust and 2011 IEEE Third International Conference on Social Computing. IEEE, 2011. p. 531-536.

COMISSÃO DE VALORES MOBILIÁRIOS. Recomendações da CVM sobre governança corporativa, $2002 . \quad$ Disponível em: <http://www.cvm.gov.br/export/sites/cvm/decisoes/anexos/0001/3935.pdf.> Acesso em: set. 2018.

COMISSÃO DE VALORES MOBILIÁRIOS. Consulta de documentos de companhias abertas. Disponível em:

http://cvmweb.cvm.gov.br/SWB/Sistemas/SCW/CPublica/CiaAb/FormBuscaCiaAb.aspx?TipoCons $\mathrm{ult}=\mathrm{c}>$ Acesso em: set. 2018.

CONNELLY, B. L. et al. More than adopters: Competing influences in the interlocking directorate. Organization Science, v. 22, n. 3, p. 688-703, 2011.

COSTA, L.; SAMPAIO, J. O.; FLORES, E. S. Diversidade de Gênero nos Conselhos Administrativos e sua Relação com Desempenho e Risco Financeiro nas Empresas Familiares. Revista de Administração Contemporânea, v. 23, n. 6, p. 721-738, 2019.

CUNHA, P. R.; PICCOLI, M. R. Influência do board interlocking no gerenciamento de resultados. Revista Contabilidade \& Finanças, v. 28, n. 74, p. 179-196, 2017.

DAL VESCO, D. G.; BEUREN, I. M. Do the board of directors composition and the board interlocking influence on performance?. BAR-Brazilian Administration Review, v. 13, n. 2, 2016.

FICH, E. M. Are some outside directors better than others? Evidence from director appointments by Fortune 1000 firms. The Journal of Business, v. 78, n. 5, p. 1943-1972, 2005.

FICH, E. M.; WHITE, L. J. Why do CEOs reciprocally sit on each other's boards?. Journal of Corporate Finance, v. 11, n. 1-2, p. 175-195, 2005. 
FRAGA, J. B.; SILVA, V. A. B. Board diversity and firm performance: an empirical investigation in the Brazilian market. Brazilian Business Review, v. 9, n. Special Ed, p. 55-77, 2012.

FONTES, B. A. S. M.; STELZIG, S. Sobre trajetórias de sociabilidade: a ideia de relé social enquanto mecanismo criador de novas redes sociais. Política \& Sociedade, v. 3, n. 5, p. 57-77, 2004.

FREEMAN, L. C. Centrality in social networks conceptual clarification. Social networks, v. 1, n. 3, p. 215-239, 1978.

FREITAS, L. Q. Medidas de Centralidade em Grafos. 2010, 103f. Dissertação (Mestrado em Engenharia de Produção). UFRJ/ COPPE, Rio de Janeiro/RJ, 2010.

GOMES, T.; BEUREN, I. M.; VICENTE, E. F. R. Influence of the Characteristics of the Board of Directors on the Performance of Companies with Board Interlocking. Revista de Administração da UFSM, v. 12, n. 4, p. 645-662, 2019.

GROSSETTI, M.; BÈS, M. P. Dynamique des réseaux et des cercles. Revue d'économie industrielle, n. 103, p. 43-57, 2003.

INSTITUTO BRASILEIRO DE GOVERNANÇA CORPORATIVA. Código das Melhores Práticas de Governança Corporativa. 4.ed. São Paulo, SP: IBGC, 2009. Disponível em: <http://www.ibgc.org.br/userfiles/Codigo_julho_2010_a4.pdf.> Acesso em: set. 2018.

INSTITUTO BRASILEIRO DE GOVERNANÇA CORPORATIVA. Código das melhores práticas de governança corporativa. 5.ed. São Paulo, SP: IBGC, 2015. Disponível em: <http:// conhecimento.ibgc.org.br/Lists/Publicacoes/Attachments/21138/Publicacao-IBGCCodigoCodigodasMelhoresPraticasdeGC-5aEdicao.pdf.> Acesso em: out. 2018.

LAZZARETTTI, K.; PIEKAS, A. A. S.; JULKOVSKI, D. J. Características dos Conselhos de Administração e Desempenho das Firmas Brasileiras de Capital Aberto. Revista Gestão Organizacional, v. 12, n. 3, p. 54-71, 2019

LODERER, C.; PEYER, U. Board overlap, seat accumulation and share prices. European Financial Management, v. 8, n. 2, p. 165-192, 2002.

LUNARDI, M. A.; BARBOSA, E. T.; CUNHA, P. R. Relação entre o 'Board Interlocking' e a Persistência nos Lucros. BASE - Revista de Administração e Contabilidade da UNISINOS, v. 16, n. 4, p. 589-613, 2019.

MAGRO, C. B. D.; KLANN, R. C. Novo Olhar ao 'Board Interlocking': Evidências a partir das Redes Sociais Corporativas. Revista de Administração Pública, v. 54, n. 1, p. 121-141, 2020.

NICHOLSON, G. J.; ALEXANDER, M.; KIEL, G. C. Defining the social capital of the board of directors: An exploratory study. Journal of Management \& Organization, v. 10, n. 1, p. 54-72, 2004.

NISIYAMA, E. K.; NAKAMURA, W. T. Diversidade do conselho de administração e a estrutura de capital. Revista de Administração de Empresas, v. 58, n. 6, p. 551-563, 2018.

ORGANISATION FOR ECONOMIC CO-OPERATION AND DEVELOPMENT. OECD Corporate Governance Factbook, 2017. Disponível em: https://www.oecd.org/daf/ca/CorporateGovernance-Factbook.pdf . Acesso em: set 2018.

RIBEIRO, F.; COLAUTO, R. D. A relação entre board interlocking e as práticas de suavização de resultados. Revista Contabilidade \& Finanças, v. 27, n. 70, p. 55-66, 2016. 
Fábio Pagliarini do Nascimento, Patrícia Saltorato, Tiago Fonseca Albuquerque Cavalcanti Sigahi e Geraldo Tessarini Junior

SANTOS, R. L.; SILVEIRA, A. Di M. Board interlocking no Brasil: a participação de conselheiros em múltiplas companhias e seu efeito sobre o valor das empresas. Revista Brasileira de Finanças, v. 5, n. $2,2007$.

SANTOS, T. B. Governança corporativa aplicada a pequenas e médias empresas 2015, 66f. Monografia (Bacharelado em Ciências Contábeis). Universidade Federal do Rio Grande do Norte UFRN. Caicó/RN, Brasil, 2015.

SCHMILIVER, A. L.; TEIXEIRA, M. S.; BRANDÃO, M. D.; ANDRADE, V. D.; JUCÁ, M. N. A Presença de Mulheres Cria Valor às Empresas? Revista Pretexto, v. 20, n. 3, p. 83-97, 2019.

SCHOORMAN, F. D.; BAZERMAN, M. H.; ATKIN, R. S. Interlocking directorates: A strategy for reducing environmental uncertainty. Academy of Management Review, v. 6, n. 2, p. 243-251, 1981.

SONZA, I. B.; KLOECKNER, G. O. A governança corporativa influencia a eficiência das empresas brasileiras? Revista Contabilidade \& Finanças, v. 25, n. 65, p. 145-160, 2014.

TOMAÉL, M. I.; MARTELETO, R. M. Redes sociais de dois modos: aspectos conceituais. Transinformação, v. 25, n. 3, 2013. 


\section{Apêndice}

Apêndice A - Métricas de Centralidade Rede II

\section{Centralidade}

\begin{tabular}{|c|c|c|c|c|c|}
\hline Organização & Id & Grau & De Grau & Intermediação & Proximidade \\
\hline BANCO PAN & 1 & 15 & 0,2727 & 658,0 & 0,2895 \\
\hline CEMIG & 3 & 13 & 0,2364 & 874,5 & 0,4044 \\
\hline ELETROBRAS & 4 & 12 & 0,2182 & 839,0 & 0,3929 \\
\hline BRASKEM & 2 & 12 & 0,2182 & 477,0 & 0,2895 \\
\hline CPFL Geração de Energia S/A & 36 & 9 & 0,1636 & 118,5 & 0,3526 \\
\hline USIMINAS & 7 & 8 & 0,1455 & 675,0 & 0,3503 \\
\hline FRAS-LE & 5 & 7 & 0,1273 & 107,0 & 0,3073 \\
\hline Odebrecht S.A. & 47 & 6 & 0,1091 & 0,0 & 0,2301 \\
\hline Companhia de Concessões Rodoviárias - CCR & 27 & 6 & 0,1091 & 0,0 & 0,2301 \\
\hline Concessionaria da Rodovia Presidente Dutra S.A. & 31 & 6 & 0,1091 & 0,0 & 0,2301 \\
\hline Concessionaria S. A. Bandeirantes S.A. & 32 & 6 & 0,1091 & 0,0 & 0,2301 \\
\hline Concessionaria Ponte Rio-Niterói S.A. & 33 & 6 & 0,1091 & 0,0 & 0,2301 \\
\hline Concessionaria Rodovia dos Lagos S.A. & 34 & 6 & 0,1091 & 0,0 & 0,2301 \\
\hline BB Administração de Consórcios S.A. & 14 & 5 & 0,0909 & 0,0 & 0,3039 \\
\hline BDMG & 15 & 5 & 0,0909 & 0,0 & 0,3039 \\
\hline Fundação Banco do Brasil & 41 & 5 & 0,0909 & 0,0 & 0,3039 \\
\hline Furnas Centrais Elétricas S.A. & 42 & 4 & 0,0727 & 0,0 & 0,2973 \\
\hline Companhia Paulista de Forca e Luz. & 30 & 4 & 0,0727 & 0,0 & 0,2973 \\
\hline NOS & 50 & 4 & 0,0727 & 0,0 & 0,2973 \\
\hline Brasbunker S.A. & 17 & 3 & 0,0545 & 0,0 & 0,2273 \\
\hline Casa \& Vídeo & 24 & 3 & 0,0545 & 0,0 & 0,2273 \\
\hline Contax Participações S.A. & 35 & 3 & 0,0545 & 0,0 & 0,2273 \\
\hline Estácio Participações S.A. & 38 & 3 & 0,0545 & 0,0 & 0,2273 \\
\hline Linx S.A. & 45 & 3 & 0,0545 & 0,0 & 0,2273 \\
\hline Odebrecht TransPort & 48 & 3 & 0,0545 & 0,0 & 0,2273 \\
\hline Caixa Seguros Holding S.A. & 22 & 3 & 0,0545 & 0,0 & 0,2273 \\
\hline Cash Insurance S.A. & 25 & 3 & 0,0545 & 0,0 & 0,2273 \\
\hline Hydrothermal SA & 43 & 3 & 0,0545 & 0,0 & 0,2273 \\
\hline Amec & 10 & 3 & 0,0545 & 0,0 & 0,2865 \\
\hline BR Malls Participações S.A. & 16 & 3 & 0,0545 & 0,0 & 0,2865 \\
\hline TOTVS S.A. & 55 & 3 & 0,0545 & 0,0 & 0,2865 \\
\hline Camargo Correa S.A. & 23 & 3 & 0,0545 & 0,0 & 0,2632 \\
\hline OHG Mining & 49 & 3 & 0,0545 & 0,0 & 0,2632 \\
\hline W Consultoria e Participações & 56 & 3 & 0,0545 & 0,0 & 0,2632 \\
\hline CIEE & 26 & 2 & 0,0364 & 0,0 & 0,2750 \\
\hline Banco Clássico S.A. & 12 & 2 & 0,0364 & 0,0 & 0,3333 \\
\hline Caixa Capitalização S.A. & 18 & 2 & 0,0364 & 0,0 & 0,2263 \\
\hline Caixa Seguridade Participações S.A. & 21 & 2 & 0,0364 & 0,0 & 0,2263 \\
\hline Eternit S.A. & 39 & 2 & 0,0364 & 0,0 & 0,3179 \\
\hline Companhia De Saneamento De Minas Gerais & 29 & 2 & 0,0364 & 0,0 & 0,2910 \\
\hline Light Serviços de Eletricidade S.A. & 44 & 2 & 0,0364 & 0,0 & 0,2910 \\
\hline CODEMIG & 28 & 2 & 0,0364 & 0,0 & 0,2910 \\
\hline Diferencial Energia Participações S.A. & 37 & 2 & 0,0364 & 0,0 & 0,2910 \\
\hline FALCONI - Consultores de Resultados & 40 & 2 & 0,0364 & 600,0 & 0,3354 \\
\hline Banco do Nordeste do Brasil S.A. & 13 & 1 & 0,0182 & 0,0 & 0,2835 \\
\hline RANDON PART & 6 & 1 & 0,0182 & 0,0 & 0,2361 \\
\hline Paschoalotto Serviços Financeiros S.A. & 51 & 1 & 0,0182 & 0,0 & 0,2361 \\
\hline Sappada Participações S.A. & 53 & 1 & 0,0182 & 0,0 & 0,2254 \\
\hline Caixa Participações S.A. - Caixapar. & 20 & 1 & 0,0182 & 0,0 & 0,2254 \\
\hline PRAGMA & 52 & 1 & 0,0182 & 0,0 & 0,2835 \\
\hline Odebrecht Agroindustrial S.A. & 46 & 1 & 0,0182 & 0,0 & 0,2254 \\
\hline ABVCAP & 8 & 1 & 0,0182 & 0,0 & 0,2254 \\
\hline Ternium S.A. & 54 & 1 & 0,0182 & 0,0 & 0,2607 \\
\hline Caixa Econômica Federal. & 19 & 1 & 0,0182 & 0,0 & 0,2254 \\
\hline Banco BTG Pactual S.A. & 11 & 1 & 0,0182 & 0,0 & 0,2254 \\
\hline Anbima & 9 & 1 & 0,0182 & 0,0 & 0,2254 \\
\hline
\end{tabular}

